\title{
TO STUDY THE EFFECT OF DIETARY BLACK SEED (NIGELLA SATIVA) SUPPLEMENTATION ON THE MEAT QUALITY OF LABEO ROHITA
}

Israr Maqbool (PhD researcher), Ariana Ali (MPhil researcher), Muhammad Ashraf (PhD researcher), Tahir Shehzad (MPhil researcher), Muhammad Sarfraz (PhD researcher), Safdar Iqbal (PhD researcher), Abdul Qadeer Saad (PhD researcher).

Department of Zoology Cholistan University of Veterinary and Animal Sciences, Bahawalpur Pakistan

\begin{abstract}
:
Purpose In this study, we looked at the benefits of a Nigella sativa supplementation diet and how nonessential fatty acids were controlled in Labeo rohit. Methods For a total of 28 days, Labeo rohita were fed various supplemental diets including 0.00 percent, $1 \%$, and 2.5 percent black cumin seed. The effect of black cumin seed on Labeo rohita's fatty acid profile was investigated. Saturated fatty acids were high at the start of the trial, but they reduced after supplementation, and the difference in fatty acids between groups was statistically significant $(\leq 0.05)$. When black cumin seed was added to fish diet, it reduced saturated fatty acids (methyl heptadedecanoate and methyl stearate) while increasing unsaturated fatty acids (gamma-linolenic acid and methyl cis-5,8,11,14 eicosatetraenoic) ConclusionIn conclusion, adding 2.5 percent black cumin seed bin feed enhanced un-saturated fatty acids, which improved the quality of the fish flesh.
\end{abstract}

Key words: Labeo rohita, black cumin seed, fish meat, un saturated fatty acids.

\section{INTRODUCTION}

Aquaculture is crucial in reducing the burden on the world's aquatic resources. Aquaculture-based fish production has a substantial influence on global food security requirements for the human population (1). Herbs and herbal products used to fish feed aid growth, decrease stress, boost immunity, and protect against infectious agents (2). Nigella sativa (black cumin seed) is a spice and food preservative with antioxidant, antibacterial, antifungal, analgesic, anti-inflammatory, anticancer, antidiabetic, immunomodulator, spasmolytic, bronchodilator, and hepatoprotective effects (3).
Essential fatty acids (EFAs) assist to prevent skin and hair dryness, acne, eczema, allergies, brittle nails, rashes, and small lumps, and omega-3 fatty acids have been proven to enhance learning, memory, agerelated cognitive decline, depression, and mood problems in those in good health (4).

Eicosatetraenoic acid and docosahexaenoic acid usage in shampoo repaired damaged hair, particularly with eicosatetraenoicacid/docosahexaenoic acid 12 percent shampoo, and might prevent damaged hair with increasing eicosatetraenoic acid concentration.(5) During pregnancy, there is an improvement in neurodevelopment. (6), As a result, monthly cramps, menopausal symptoms, and depressive symptoms in middle-aged women are reduced, as are the chances of miscarriage and pregnancy problems (7), Increased lipid accumulation in hair shaft impacts haircoat shine, glossiness, and softness during fur development, which has a positive effect on hair and skin quality. Polyunsaturated fatty acids are essential in the treatment of cardiovascular disease, type 2 diabetes, inflammatory diseases, and autoimmune disorders. Docosahexaenoic acid is required for the development of the embryonic brain and eye retina (8). The effects of omega-3 fatty acids on rheumatoid arthritis, mental health problems such as schizophrenia, and bipolar disorder (9). In the human population, and cognition reduce the risk of heart failure and stroke (10). As well as its beneficial effects on dry eye, neurological diseases, growth, development, depression, and eyesight (11). Reduce the weight loss cachexia during cancer therapy (12).

\section{STUDY DESIGN AND METHODOLOGY}

Labeo rohita fingerlings were acquired from a commercial fish farm and hatchery in Manawan, 
Lahore, for this study. The fingerlings were acclimated in glass aquaria at the Fisheries Research and Training Institute in Lahore's Nutrition Laboratory. During the trial, the fish were fed commercial food twice a day. Fish were divided into three groups, each with 20 fish representing three replicates, and fed for a total of 28 days. Nigella sativa seed was added to the diet in three different amounts: $0.00 \%, 1 \%$, and $2.5 \%$.

\section{QUANTITY OF DOSES}

Commercial carp feed obtained from private firm Oryza organics pvtltd was utilized in the research. Using a spraying technique, cold compressed black cumin seed was introduced to fish feed, which was then mixed until homogenized. In the research, the amount of black cumin seed added to the basal diet was $0.00 \%, 1 \%$, and 2.5 percent.

\section{FATTY ACID PROFILE}

The fatty acid profile was analyzed by gas chromatography clarus 500 with auto sampler (Perkin Elmer, USA) equipped with a flame ionization detector and fused silica capillary sue column (IDX $0.25 \mu \mathrm{m}$ BP20 $0.25 \mu \mathrm{m}$, USA). The oven temperature was held at $140{ }^{\circ} \mathrm{C}$ for $5 \mathrm{~min}^{-1}$, raised to $200{ }^{\circ} \mathrm{C}$ at the rate of $4{ }^{\circ} \mathrm{Cmin}^{-1}$ and held at $240^{\circ} \mathrm{C}$ at rate $1{ }^{\circ} \mathrm{Cmin}^{-1}$, while the injector and the detector temperature were set at $240{ }^{\circ} \mathrm{C}$ and $280^{\circ} \mathrm{C}$, respectively. Fatty acids were identified by comparing the retention times of FAME with the standard 37 component FAME mixture. Two replicate GC analyses were performed and the results expressed in GC area $\%$ as a mean value and \pm standarderror of mean.

Statistical analysis: GraphPad prism 8 was used to examine the data collected. The results were determined using a one-way ANOVA followed by a post-hoc test (Tukey's test) to determine the difference between the experimental groups.

\section{RESULTS}

Acid monoesters linolelaidic acid significantly decreased while, gamma-linolenic Saturated fatty acid monoesters, methyl heptadedecanoate and methyl stearate significantly decreased in $1 \%, 2.5 \%$ N.S. supplemented diet groups as compared to control group. Mono-unsaturated fatty acid monoesters cis-10-pentadecanoic acid significantly decreased while, cis-9-oleic acid and trans-9-elaidic acid significantly increased in $1 \%$ and 2.5\% N.S. supplemented diet groups as compared to control group. Poly-unsaturated fatty acid and methyl cis-5,8,11,14 eicosatetraenoic acid significantly increased in $1 \%$ and $2.5 \%$ N.S. supplemented diet groups as compared to control group.

Table: 4.1: $\quad$ The muscles fatty acid profile (\% total fatty acids) of Labeo rohita fingerlings fed on varying levels of Nigella sativa seeds supplemented diets for 28 days.

\begin{tabular}{|l|l|l|l|l|}
\hline \multicolumn{2}{|c|}{} & \multicolumn{2}{l|}{ Experimental Groups } \\
\cline { 3 - 5 } & \multirow{2}{*}{ Fatty acid monoesters (FAMEs) } & $\begin{array}{l}\text { Group-I } \\
\text { (Basal diet + 0.0 \% } \\
\text { Nigella sativa) }\end{array}$ & $\begin{array}{l}\text { Group-II } \\
\text { (Basal diet + 1.0 \% } \\
\text { Nigella sativa) }\end{array}$ & $\begin{array}{l}\text { Group-III } \\
\text { (Basal diet + 2.5 \% } \\
\text { Nigella sativa) }\end{array}$ \\
\hline C12:0 & Methyl undecanoate & ND & ND & $7.164 \pm 0.234$ \\
\hline C14:0 & Methyl tridecanoate & 14.614 & ND & ND \\
\hline C18:0 & Methyl heptadedecanoate & $480.147 \pm 0.456$ & $267.167 \pm 0.932 *$ & $177.006 \pm 0.123 *$ \\
\hline C19:0 & Methyl stearate & $363.056 \pm 0.267$ & $246.373 \pm 0.781 *$ & $91.403 \pm 0.743 *$ \\
\hline C21:0 & Methyl arachidate & ND & ND & $1428.39 \pm 0321$ \\
\hline C22:0 & Methyl heneicosanoate & $1285.001 \pm 0.236$ & ND & ND \\
\hline C23:0 & Methyl behenate & ND & $561.456 \pm 0.561$ & $904.964 \pm 1.656$ \\
\hline C24:0 & Methyl tricosanoate & ND & ND & $1800.215 \pm 0.878$ \\
\hline ESFA & & $50.16 \pm 0.134$ & $32.19 \pm 0.161 *$ & $37.16 \pm 0.983 *$ \\
\hline
\end{tabular}


International Journal of Engineering Applied Sciences and Technology, 2021

Vol. 6, Issue 5, ISSN No. 2455-2143, Pages 155-159

Published Online September 2021 in IJEAST (http://www.ijeast.com)

\begin{tabular}{|l|l|l|l|l|}
\hline C15:1n10c & Cis-10 pentadecanoic acid & $151.082 \pm 0.136$ & $13.115 \pm 0.178^{*}$ & $49.934 \pm 0.563^{*}$ \\
\hline C17:1n9 & Methyl palmitoleate & $693.006 \pm 0.333$ & $431.151 \pm 0.456$ & ND \\
\hline C171n10c & $\begin{array}{l}\text { Cis-10 heptadedecanoic } \\
\text { acid }\end{array}$ & $587.445 \pm 0.376$ & ND & ND \\
\hline C171n10c & $\begin{array}{l}\text { Cis-10 heptadedecanoic } \\
\text { acid }\end{array}$ & $587.445 \pm 0.376$ & ND & ND \\
\hline C18 1n9c & Cis-9-oleic acid & $729.289 \pm 0.198$ & $223.12 \pm 0.239^{*}$ & $483.617 \pm 0.568^{*}$ \\
\hline C18 1n9t & Trans-9-elaidic acid & $536.59 \pm 0.201$ & $5.774 \pm 0.132^{*}$ & $5338.418 \pm 0.411^{*}$ \\
\hline$\sum$ MUFAs & & $29.87 \pm 0.678$ & $42.32 \pm 0.110^{*}$ & $34.12 \pm 0.667^{*}$ \\
\hline C18:2n9t & Linolelaidic acid & $4429.297 \pm 0.139$ & $501.011 \pm 0.100^{*}$ & $998.231 \pm 0.268^{*}$ \\
\hline C18:3n6 & Gamma-linolenic acid & $410.868 \pm 0.021$ & $887.456 \pm 0.067 *$ & $1184.637 \pm 0.139^{*}$ \\
\hline C19:2n9 & Methyl linoleate & $275.576 \pm 0.161$ & ND & ND \\
\hline C21:2n11c & $\begin{array}{l}\text { Cis-11, 14-eicosadieniic } \\
\text { acid }\end{array}$ & ND & $636.138 \pm 0.123$ & $1728.346 \pm 0.156$ \\
\hline C21:4n5c & $\begin{array}{l}\text { Methyl Cis-5, 8, 11, 14- } \\
\text { eicosatetraenoic acid }\end{array}$ & $890.252 \pm 0.108$ & $998.146 \pm 0.992^{*}$ & $1280.777 \pm 0.455^{*}$ \\
\hline$\sum$ PUFAs & & $19.95 \pm 0.563$ & $25.49 \pm 0.642^{*}$ & $28.72 \pm 0.130^{*}$ \\
\hline
\end{tabular}

Values are given as mean \pm S.E.M. Means in the same row with asterisks are significantly different $(* P<$ $0.05) . S F A=$ saturated fatty acids; MUFAs= mono-unsaturated fatty acids; PUFAs= polyunsaturated fatty acids; $\mathrm{ND}=$ not detected

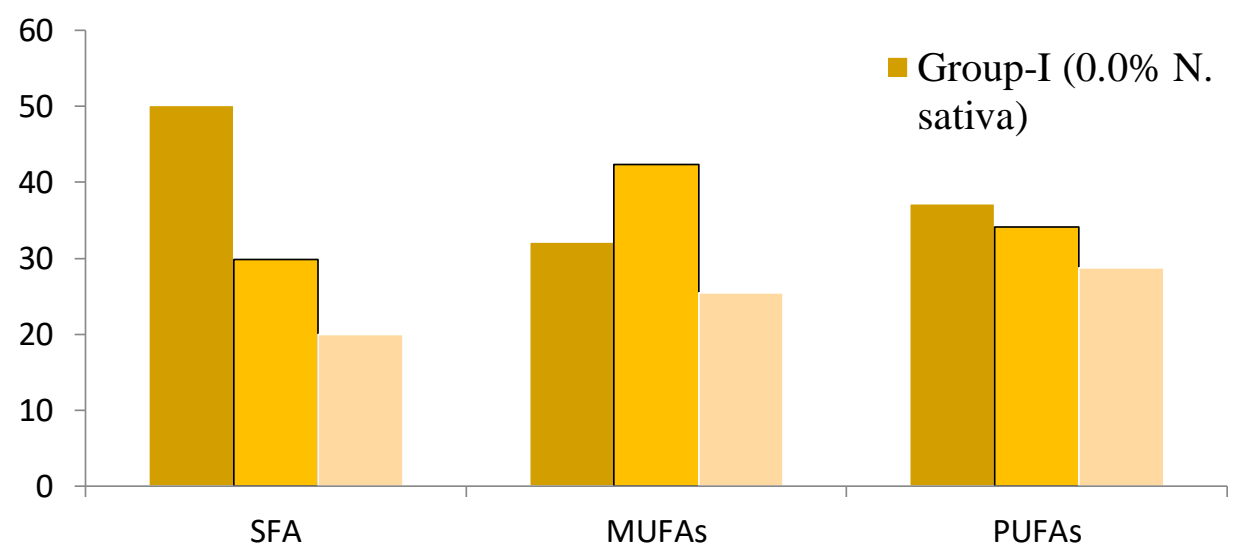

Figure 4.1: $\quad$ Percentage fatty acid groups in the dorsal muscles of rohu fingerlings fed on diets containing varying levels of Nigella sativa seeds for 28 days. Where; SFA= saturated fatty acids; MUFAs= mono-unsaturated fatty acids; PUFAs= polyunsaturated fatty acids.

\section{DISCUSSION}

Nigella sativa seeds were added to the diet and had a positive influence on the lipid profile.
When compared to controls, it reduced TG, TC, and LDL cholesterol while increasing HDL cholesterol. 


\section{International Journal of Engineering Applied Sciences and Technology, 2021 \\ Vol. 6, Issue 5, ISSN No. 2455-2143, Pages 155-159 \\ Published Online September 2021 in IJEAST (http://www.ijeast.com)}

Abd El-Hack et al (13) reported that Nigella sativa has high-quality nutritive values as evident from the studies performed to know about nutrients, protein content and omega 3 fatty acids. The extracts of the Nigella sativa seed have significant therapeutic effects against variety of ailments. The seeds/oil has various health benefits as it lessen blood pressure, raise respiration and provide valuable nutraceuticals and pharmaceutical products to boost growth.

$\mathrm{Oz}$ et al (14) who reported the effects of black cumin oil (Nigella sativa) in liver fatty acids of rainbow trout (Oncorhynchus mykiss). This decreased the saturated fatty acids and increased polyunsaturated fatty acids (eicosapentaenoic acid and docosahexaenoic acid) in rainbow liver tissues supplemented with black seed. This is because black cumin seed have higher raw protein, raw cinder, lipid and dry matter.

Omolo et al (15) agreed with our results who reported the reduction in level of saturated fatty acids in meat of rohu was observed when fed with supplemented diet Spirulina platensis when compared to control group while, poly-unsaturated fatty acids eicosapentaenoic acid and docosahexaenoic acid increased because tilapia has capability of converting dietary alpha- linolenic acid to poly-unsaturated fatty acids.

Ayisi et al (16) reported the effects of palm oil on meat quality of fish muscle and liver tissues. A significant decreased in saturated fatty acids because dietary fatty acid profiles and increase polyunsaturated fatty acids especially eicosapentaenoic acid, docosahexaenoic acid fed omega 6 decreased with increase the quantity of dietary palm oil in Nile tilapia. Low value of palm oil improved the meat quality of fish and increase market value.

\section{CONCLUSION}

In Labeo rohita fingerlings, eating Nigella sativa seeds improves their lipid profile by lowering triglycerides, total cholesterol, and LDL cholesterol while boosting HDL cholesterol. Actually unsaturated fatty acid play important role to improve the meat quality in fishes.

\section{REFERENCES}

1. Lee, M. K., and Yoo, S. H. (2014). The role of the capture fisheries and aquaculture sectorsin the Korean national economy: an input-output analysis. The Journal of Marine Policy, 44,448-456.
2. Shakya, S. R., and Labh, S. N. (2014). Medicinal uses of garlic (Allium sativum) improve fish health and acts as an immunostimulant in aquaculture. European journal of Biotechnology and Bioscience, 2(4), 44-47.

3. Ali, B. H., and Blunden, G. (2003). Pharmacological and toxicological properties of Nigella sativa. Phytotherapy Research Journal Pharmacological toxicologyI,17 (4), 299-305.

4. McIntyre, M. (2018). Omega 3 and fish oil benefits for men. https://malehealthreview.com.

5. Lee, B. R., Lee, O. S., Kang, T. J., and Lim, S. C. (2011). Development of shampoo formulated by EPA for the damaged hair. Korean Journal of Clinical Pharmacy, 21(3), 256-269.

6. Saini, P. (2018). 6 Amazing Benefits of Fish Oil for Women. Skin. American Journal of Clinical Nutrition. 89, 641-651.

7. Coletta, J. M., Bell, S. J., and Roman, A. S. (2010). Omega-3 fatty acids and pregnancy. Reviews in Obstetrics and Gynecology, 3(4), 163.

8. Combarros, D., Castilla-Castaño, E., Lecru, L. A., Pressanti, C., Amalric, N., and Cadiergues, M. C. (2020). A prospective, randomized, double blind, placebocontrolled evaluation of the effects of an n-3 essential fatty acids supplement on clinical signs and fatty acid concentrations in the erythrocyte membrane, hair shafts and skin surface of dogs with poor quality coats. Prostaglandins, Leukotrienes and Essential Fatty Acids, 159, 102140

9. Jabeen, F., and Chaudhry, A. S. (2011). Chemical compositions and fatty acid profiles of three freshwater fish species. The Journal of Food chemistry, 125(3), 991-996.

10. Deckelbaum, R. J., and Torrejon, C. (2012). The omega- 3 fatty acid nutritional landscape: health benefits and sources. The Journal of Nutrition, 142(3), 587-591

11. Gogus, U., and Smith, C. (2010). N-3 omega fatty acids. a review of current knowledge, International Journal of Food Science and Technology, 45(3), 417-436.

12. Feuerstein, S., Coric, A., and Sanfilippo, L. C. (2010). Omega 3 fatty acid formulations. Washington, DC: U.S. Patent and Trademark Office, 7,652-668. 
13. Abd El-Hack, M. E., Alagawany, M., Farag, M. R., Tiwari, R., Karthik, K., and Dhama, K. (2016). Nutritional, healthy and therapeutic efficacy of black cumin (Nigella sativa) in animals, poultry and humans. International Journal of Pharmacology, 12(3), 232-248.

14. Oz, M. (2017). Effect of black cumin oil (Nigella sativa) on liver fatty acid profile of rainbow trout (Oncorhynchus mykiss). The Journal of Veterinary Microbiology, 28(1), 55-59.

15. Omolo, K., M. I., Onyango, A., Magoma, G., Munguti, J., and Ogila, K. (2017). Dietary effect of varying linseed oil compositions on growth response, survival and polyunsaturated fatty acid levels in tilapia (Oreochromis niloticus). International Journal of Fisheries and Aquaculture, 9(4), 31-41.

16. Ayisi, C. L., Zhao, J., and Rupia, E. J. (2017). Growth performance, feed utilization, body and fatty acid composition of nile tilapia (Oreochromis niloticus) fed diets containing elevated levels of palm oil. Aquaculture and Fisheries, 2, 67-77. 